\title{
Placental glucose transport and utilisation is altered at term in insulin-treated, gestational-diabetic patients
}

\author{
D. T.D.Osmond ${ }^{1}$, R.G.King ${ }^{2}$, S.P. Brennecke ${ }^{3}$, N.M. Gude ${ }^{1}$ \\ ${ }^{1}$ Department of Perinatal Medicine, Royal Women's Hospital, Carlton, Victoria, Australia \\ ${ }^{2}$ Department of Pharmacology, Monash University, Clayton, Victoria, Australia \\ ${ }^{3}$ Department of Obstetrics and Gynaecology, University of Melbourne, Royal Women's Hospital, Carlton, Victoria, Australia
}

\section{Abstract}

Aims/hypothesis. We have previously shown that placentae from patients with gestational diabetes mellitus who did not receive insulin had lower glucose transport and utilisation than non-diabetic control subjects. To assess the placental glucose handling characteristics of women with gestational diabetes mellitus receiving insulin, we examined glucose transport and utilisation in placentae from three groups of women after term delivery: those with gestational diabetes mellitus and receiving insulin $(n=9$, insulin group); those with gestational diabetes mellitus and not receiving insulin ( $n=10$, no insulin group); and those with normal, non-diabetic pregnancies $(n=9$, control group).

Methods. Dual perfusion of an isolated placental lobule was done using maternal glucose concentrations of 4, 8, 16 and $24 \mathrm{mmol} / \mathrm{l}$. Glucose and L-lactate concentrations in the maternal and fetal effluents were measured. Direct glucose transfer from the maternal to the fetal effluent was measured using ${ }^{14} \mathrm{C}$-D-glu-

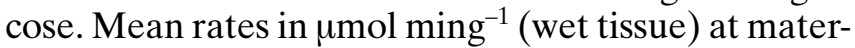
nal glucose concentration of $8 \mathrm{mmol} / \mathrm{l}$ are shown.

Results. Glucose uptake from the maternal perfusate (insulin group 0.57, no insulin group 0.30) and net glucose transfer to the fetal effluent (insulin group 0.41 , no insulin group 0.20 ) both increased in the placentae of women receiving insulin compared with the diabetic group not receiving insulin. Both groups of patients had lower placental glucose utilisation than the control group (insulin group 0.16, no insulin group 0.10 , control group 0.25 ).

Conclusion/interpretation. These results suggest that materno-fetal glucose transport increases in the placentae of women with gestational diabetes mellitus who receive insulin compared with those women who do not receive insulin. [Diabetologia (2001) 44: 1133-1139]

Keywords Gestational diabetes, human placenta, glucose metabolism, in vitro perfusion.
The primary energy-releasing substrate for fetal growth and development is glucose. As glycaemic activity in the fetal circulation is influenced by the activity of the maternal circulation, any condition that causes variation in glucose concentrations in mothers will also affect the growth and development of their

Received: 19 February 2001 and in revised form: 17 April 2001

Corresponding author: N.M.Gude, Department of Perinatal Medicine, Royal Women's Hospital, 132 Grattan Street, Carlton Victoria 3053, Australia, E-mail: nmgude@ariel.its.uni melb.au

Abbreviations: GLUT1, glucose transporter protein 1; GDM, gestational diabetes mellitus; GTT, glucose tolerance test fetuses. Gestational diabetes mellitus (GDM) is one such condition affecting glucose concentration. It has prevalence rates in Australia estimated at between 3 and $10 \%$, depending on the population studied but in some ethnic populations the prevalence is much higher [1-3].

Offspring of women affected by diabetes are more likely to develop diabetes mellitus and obesity later in life [4]. This observation, as well as evidence that the development of diabetes is more closely related to the state of mothers' rather than fathers, health, suggests that the intrauterine environment could be important $[5,6]$. Placental function could be an intrauterine factor affecting metabolic out- 
comes although little is known about this aspect of placental function.

We have previously shown, using an human ex vivo perfused placental lobule model, that the transfer of glucose from the maternal perfusate to the foefal effluent is reduced in patients with GDM who have been following only nutritional and exercise advice, compared with the placentae of those women whose pregnancies are uncomplicated by diabetes [7].

It has been shown that insulin at physiological concentrations increased the rate of glucose uptake into cultured first trimester trophoblasts by increasing GLUT1 expression [8]. Thus, we hypothesised that exogenous insulin treatment would alter placental glucose transfer to the fetus in GDM patients compared with GDM patients not requiring insulin therapy. Thus, this study aimed to examine glucose transport and utilisation in intact human placental lobules from women with GDM and receiving dietary advice alone, women with GDM and receiving insulin therapy, and women whose pregnancies were not complicated by any form of diabetes.

\section{Materials and methods}

All experimental procedures in this study were approved by the Royal Women's Hospital Research and Ethics Committees and were in accordance with the National Health and Medical Research Council of Australia guidelines. Written, informed consent was obtained from all patients participating in the study.

Placental collection. Placentae were collected at term following normal vaginal delivery or Caesarean section from women who had gestational diabetes mellitus treated with dietary advice alone (GDM-Diet, $n=10$ ), gestational diabetes mellitus treated with insulin therapy (GDM-Insulin, $n=9$ ) or who had normal non-diabetic pregnancies (Control group, $n=9$ ). Placentae from pregnancies in which the infant birth weight was greater than the 95th centile for gestational age were excluded from this study, because excessive fetal growth could interact with placental glucose transport. At 26 to 28 weeks patients were tested for GDM with a glucose tolerance test (GTT) done in the morning after an overnight fast and using a $75 \mathrm{~g}$ glucose load. A diagnosis of GDM was made if the fasting plasma glucose concentration was greater than or equal to $5.0 \mathrm{mmol} / \mathrm{l}$ and/or the 2-h plasma glucose concentration after a GTT was greater than or equal to $8.0 \mathrm{mmol} / \mathrm{l}$. Patients diagnosed with GDM were given advice on nutrition and exercise and trained in blood glucose monitoring of themselves. Progress was monitored by a diabetes nurse educator. If hyperglycaemia persisted (fasting blood glucose $>5.5 \mathrm{mmol} / \mathrm{l}$ or $2-\mathrm{h}$ post prandial $>7.0 \mathrm{mmol} / \mathrm{l}$ ), the patient was referred to an endocrinologist and began insulin therapy. This protocol was based on the recommendations of the Australian Diabetes in Pregnancy Society 1999 [9]. No information was available regarding vitamin or iron supplements taken by the women during pregnancy.

Placental perfusion. Bilateral perfusion of a single placental lobule with a modified Krebs solution was begun within
20 min of delivery. The perfusion technique was a modification of a method previously described $[7,10]$. A suitable fetal vein and artery pair on the surface of the chorionic plate leading to a peripheral lobule was cannulated and perfused through the artery using a Masterflex perfusion pump (model 7554.00 with pump head 7013; Cole-Parmer Instruments, Vernon Hills, Ill., USA) at a constant flow rate of $5 \mathrm{ml} / \mathrm{min}$. The Krebs solution, which contained the following (mmol/l): $\mathrm{NaCl} 97.0, \mathrm{NaHCO}_{3}$ 24.4, $\mathrm{KCl} 3.0, \mathrm{KH}_{2} \mathrm{PO}_{4} 1.2, \mathrm{CaCl}_{2} .2 \mathrm{H}_{2} \mathrm{O} 1.89, \mathrm{MgSO}_{4} .7 \mathrm{H}_{2} \mathrm{O}$ 1.0, glucose 3.0 ( $\mathrm{pH} 7.4$ ), was equilibrated with $95 \%$ oxygen and $5 \%$ carbon dioxide. The maternal component of the lobule was also continually perfused with Krebs solution with varying glucose concentrations at a flow rate of $10 \mathrm{ml} / \mathrm{min}$ using two pieces of plastic tubing inserted through the basal plate into the intervillous space. The whole placenta was supported on a perspex frame within a laboratory incubator (EI40; Thermoline Scientific, Wetherill Park, NSW, Australia) and maintained at $37{ }^{\circ} \mathrm{C}$. Fetal arterial inflow perfusion pressure was measured by a Statham transducer (P23AC; GultonStratham, Costa Mesa, Calif., USA) and Maclab4 and Chart software (version 3.2, ADInstruments, Castle Hill, NSW, Australia). At the end of the experiment the perfused lobule was removed by dissection and weighed.

Glucose utilisation studies. The glucose concentration of the fetal perfusate was maintained at $3.0 \mathrm{mmol} / \mathrm{l}$ throughout the experiment. The glucose concentration of the maternal perfusate was maintained at $4 \mathrm{mmol} / \mathrm{l}$ for the first $30 \mathrm{~min}$ of perfusion, while the lobule was cleared of blood. The maternal glucose concentration was then changed at random to $4,8,16$ or $24 \mathrm{mmol} / \mathrm{l}$. After $30 \mathrm{~min}$ of perfusion at each of these glucose concentrations, ${ }^{14} \mathrm{C}(\mathrm{U})$-D-glucose $(1 \mu \mathrm{Ci} / \mathrm{ml})$ and ${ }^{3} \mathrm{H}$-L-glucose $(1 \mu \mathrm{Ci} / \mathrm{ml})$ were simultaneously infused into the maternal perfusate at $0.1 \mathrm{ml} / \mathrm{min}$ for $21 \mathrm{~min}$. The latter period of time has been shown by preliminary experiments to be sufficient for the rate of ${ }^{14} \mathrm{C}$-D-glucose and ${ }^{3} \mathrm{H}$-L-glucose transfer to the fetal effluent to reach equilibrium. D-glucose is the biologically active molecule carried by glucose transporters, while L-glucose is its stereoisomer and used as a marker of non-facilitated diffusion. Unless stated otherwise, we used D-glucose. Samples of fetal and maternal effluent were collected in 1-min intervals for the final $3 \mathrm{~min}$ of infusion. Infusion was stopped once the samples had been collected and the next maternal glucose concentration perfused. This procedure was repeated until samples had been collected for each of the $4,8,16$ or $24 \mathrm{mmol} / \mathrm{l}$ maternal glucose concentrations for each placenta. The perfusion of each maternal glucose concentration took $51 \mathrm{~min}$ and the entire experiment was completed within $4.5 \mathrm{~h}$. The samples collected for the 4, 8, 16 or $24 \mathrm{mmol} / \mathrm{l}$ maternal glucose concentrations were centrifuged immediately at $3000 \mathrm{rpm}$ for $5 \mathrm{~min}$ to remove any trace of blood and assayed fresh for glucose and Llactate using a YSI 2300 analyser (YSI, Yellow Springs, Ohio, USA). The concentrations of ${ }^{14} \mathrm{C}$-D-glucose and ${ }^{3} \mathrm{H}$-L-glucose in the sample were determined by liquid scintillation spectroscopy (Wallac 1409 Liquid Scintillation Counter, Pharmacia, Wallac Oy, Turku, Finland) and converted to disintegrations per min (DPM; Wallac Multicalc Advanced version 2.60, Pharmacia).

The following rates were calculated (all expressed as $\mu$ mol$\min ^{-1} \mathrm{~g}^{-1}$ [fresh weight]):

1. Net uptake rate of glucose from the maternal perfusate: $\left\{\left([\mathrm{G}]_{\mathrm{MP}}-[\mathrm{G}]_{\mathrm{ME}}\right) \cdot \mathrm{V}_{\mathrm{M}}\right\} / \mathrm{W}$

2. Net transfer rate of glucose to the fetal effluent: $\left\{\left([\mathrm{G}]_{\mathrm{FE}}-\right.\right.$ $\left.[\mathrm{G}]_{\mathrm{FP}}\right) \cdot \mathrm{V}_{\mathrm{F}} \mathrm{J} / \mathrm{W}$

3. Net utilisation rate of glucose by the placenta: Equation 1 Equation 2 
4. Direct transfer rate of glucose to the fetal effluent: $\left\{\mathrm{G}_{\mathrm{FE}}^{\mathrm{C} 14} \cdot[\mathrm{G}]_{\mathrm{MP}} \cdot \mathrm{V}_{\mathrm{F}}\right\} /\left\{\mathrm{G}_{\mathrm{MP}}^{\mathrm{C} 14} \cdot \mathrm{W}\right\}$

5. Release of lactate into the maternal effluent: $\left(\mathrm{L}_{\mathrm{ME}} \cdot \mathrm{V}_{\mathrm{M}}\right) / \mathrm{W}$ 6. Release of lactate into the fetal effluent: $\left(\mathrm{L}_{\mathrm{FE}} \cdot \mathrm{V}_{\mathrm{F}}\right) / \mathrm{W}$

where $[\mathrm{G}]_{\mathrm{MP}}$ is the maternal perfusate glucose concentration $(\mu \mathrm{mol} / \mathrm{ml}) ;[\mathrm{G}]_{\mathrm{ME}}$ is the maternal effluent glucose concentration $(\mu \mathrm{mol} / \mathrm{ml}) ;[\mathrm{G}]_{\mathrm{FP}}$ is the fetal perfusate glucose concentration $(\mu \mathrm{mol} / \mathrm{ml}) ;[\mathrm{G}]_{\mathrm{FE}}$ is the fetal effluent glucose concentration $(\mu \mathrm{mol} / \mathrm{ml}) ; \mathrm{V}_{\mathrm{M}}$ is the maternal perfusion rate $(\mathrm{ml} / \mathrm{min}) ; \mathrm{V}_{\mathrm{F}}$ is the fetal perfusion rate $(\mathrm{ml} / \mathrm{min}) ; \mathrm{W}$ is the perfused lobule weight (grams wet weight); $\mathrm{G}^{\mathrm{C} 14} \mathrm{FE}$ is the ${ }^{14} \mathrm{C}$-D-glucose activity in the fetal effluent $(\mathrm{dpm} / \mu \mathrm{mol}) ; \mathrm{G}^{\mathrm{C} 14}{ }_{\mathrm{MP}}$ is the ${ }^{14} \mathrm{C}$-D-glucose activity in the maternal perfusate $(\mathrm{dpm} / \mu \mathrm{mol}) ; \mathrm{L}_{\mathrm{ME}}$ is the lactate concentration in the maternal effluent $(\mu \mathrm{mol} / \mathrm{ml}) ; \mathrm{L}_{\mathrm{FE}}$ is the lactate concentration in the fetal effluent $(\mu \mathrm{mol} / \mathrm{ml})$.

Thus, net glucose transfer rate was calculated from the difference between the glucose concentration in the fetal perfusate and the glucose concentration in the fetal effluent taking into account movement to and from the fetal compartment. The direct transfer rate of glucose to the fetal effluent also involves ${ }^{14} \mathrm{C}$-D-glucose infusion into the maternal perfusate and its detection in the fetal effluent, providing a measure of the rate of unidirectional glucose transfer from the maternal compartment to fetal compartment.

In addition, to assess total placental handling of glucose, net glucose transfer to the fetal effluent at $8 \mathrm{mmol} / \mathrm{l} \mathrm{maternal}$ glucose was multiplied by the placental weight for each of the placentae studied. The value $8 \mathrm{mmol} / \mathrm{l}$ was chosen for this calculation because it falls between the fasting and 2-h post prandial glucose concentrations for all groups measured.

Finally, the diffusion of ${ }^{3} \mathrm{H}-\mathrm{L}$-glucose to the fetal effluent, was expressed as the ratio: $\mathrm{G}^{\mathrm{L}}{ }_{\mathrm{FE}} / \mathrm{G}^{\mathrm{L}}{ }_{\mathrm{MP}}$ where $\mathrm{G}^{\mathrm{L}}{ }_{\mathrm{FE}}$ is the ${ }^{3} \mathrm{H}-\mathrm{L}-$ glucose activity in the fetal effluent $(\mathrm{dpm} / \mu \mathrm{mol})$ and $\mathrm{G}^{\mathrm{L}}{ }_{\mathrm{MP}}$ is the ${ }^{3} \mathrm{H}$-L-glucose in the maternal perfusate $(\mathrm{dpm} / \mu \mathrm{mol})$.

Statistical analysis. Statistical analysis was done by SPSS for Windows Student Version (Release 9.0.1, 1999, SPSS). All data are presented as means \pm SEM. Significant differences between the mean points on the lines were determined using two-way analysis of variance (ANOVA) for condition and maternal glucose concentration and the $t$ test with Bonferroni correction. Individual lines were also analysed by one-way ANO$\mathrm{VA}$, as were values for total placental glucose handling. A value of $p<0.05$ was considered statistically significant.

Drugs and chemicals. All chemicals for the Krebs solution were obtained from British Drug Houses (Merck, Kilsyth, Victoria, Australia), except magnesium sulphate, which was from Sigma (St Louis, Mont., USA) and potassium dihydrogen phosphate from ICN Biochemicals (Cleveland, Ohio, USA). ${ }^{3} \mathrm{H}$-L-glucose $(0.1 \mathrm{Ci} / \mathrm{ml})$, and ${ }^{14} \mathrm{C}(\mathrm{U})$-D-glucose $(0.1 \mathrm{mCi} / \mathrm{ml})$ were obtained from Dupont NEN (Boston, Mass., USA).

\section{Results}

The characteristics of the pregnancies of the control and GDM patients from which placental samples were obtained for the study are shown in Table 1. Where possible, patients in the three groups were matched for gestation, parity and gravidity. However, the GDM-Insulin group had a shorter gestation than the control group $(p<0.05)$. This biological difference was not considered important for the current
Table 1. Characteristics of GDM and control pregnancies from which placentae were studied (SEM)

\begin{tabular}{lccc}
\hline Category & Control & GDM-Diet & $\begin{array}{l}\text { GDM- } \\
\text { Insulin }\end{array}$ \\
\hline$N$ & 9 & 10 & 9 \\
Maternal age (years) & $30.1(2.1)$ & $34.8(1.3)$ & $33.7(1.7)$ \\
Maternal weight (kg) & $62.2(2.5)$ & $62.4(5.3)$ & $76.5(4.9)$ \\
Gestation (weeks) & $39.3(0.4)$ & $38.6(0.37)$ & $38.0(0.17)^{\mathrm{a}}$ \\
Gravidity & $2.7(0.6)$ & $3.9(0.9)$ & $4.0(0.8)$ \\
Parity & $2.3(0.5)$ & $2.8(0.7)$ & $3.3(0.7)$ \\
Infant weight (g) & $3404(85)$ & $3348(84)$ & $3251(121)$ \\
Placental weight (g) & $642(32)$ & $734(62)$ & $581(17)$ \\
Perfused lobule (g) & $23.2(3.6)$ & $22.3(3.0)$ & $16.5(1.9)$ \\
HbA 1c $_{\text {c }}$ ) & & $6.0(0.2)$ & $5.9(0.3)$ \\
Glucose & & & \\
$\rightarrow$ Fasting & & $5.00(0.32)$ & $5.1(0.34)$ \\
$\rightarrow$ 2 h & & $9.41(0.65)$ & $9.18(0.47)$ \\
\hline Normal & &
\end{tabular}

Normal range, $\mathrm{Hb}_{\mathrm{A} 1 \mathrm{c}} 4.7$ to $6.4 \%$, fasting plasma glucose $<5.0 \mathrm{mmol} / 1,2$-h post GTT plasma glucose $<8.0 \mathrm{mmol} / \mathrm{l}$ a Significantly different from control

study. There were no other significant differences in patient, or placental characteristics between groups. The glycated haemoglobin $\left(\mathrm{HbA}_{1 \mathrm{C}}\right)$ measurement between 31 and 35 weeks (recorded only for the two GDM groups) was taken as an indicator of longterm glucose control. The normal range for human pregnancy is $4.7-6.4 \%$, and the mean recorded values fall within this range. The fasting and 2-h post glucose challenge $(75 \mathrm{~g})$ glucose concentrations were also recorded. There were no significant differences between the GDM groups in $\mathrm{Hb}_{\mathrm{A} 1 \mathrm{c}}$, fasting glucose or 2-h glucose concentrations.

Mean net uptake of glucose from the maternal perfusate (Fig. 1) rose with increasing maternal glucose concentration for all groups $(p<0.001$, for each group by one-way ANOVA). Mean net uptake of glucose was reduced in the GDM-Diet group compared with both the GDM-Insulin group $(p<0.001$; ANOVA) and the non-diabetic control subjects $(p<0.001)$. There was no significant difference, however, between the GDM-Insulin group and the nondiabetic group. Mean net glucose transfer to the fetal effluent (Fig.2) also rose with increasing maternal glucose concentration for all groups $(p<0.001$, oneway ANOVA). Mean net glucose transfer was reduced in the GDM-Diet group compared with the GDM-Insulin group $(p<0.001)$. There was no significant difference, however, between either of the diabetic groups and the control group. Direct maternofetal glucose transfer rose with increasing maternal glucose concentration for all groups $(p<0.001$; oneway ANOVA). Direct materno-fetal glucose transfer for the GDM-Diet group was reduced compared with the other two groups but the reduction was not significant. Means $( \pm \mathrm{SEM})$ rates $\left(\mu \mathrm{molmin}^{-1} \mathrm{~g}^{-1}\right)$ for direct transfer at glucose concentrations of $4,8,16$ and $24 \mathrm{mmol} / \mathrm{l}$ respectively were: control group, 


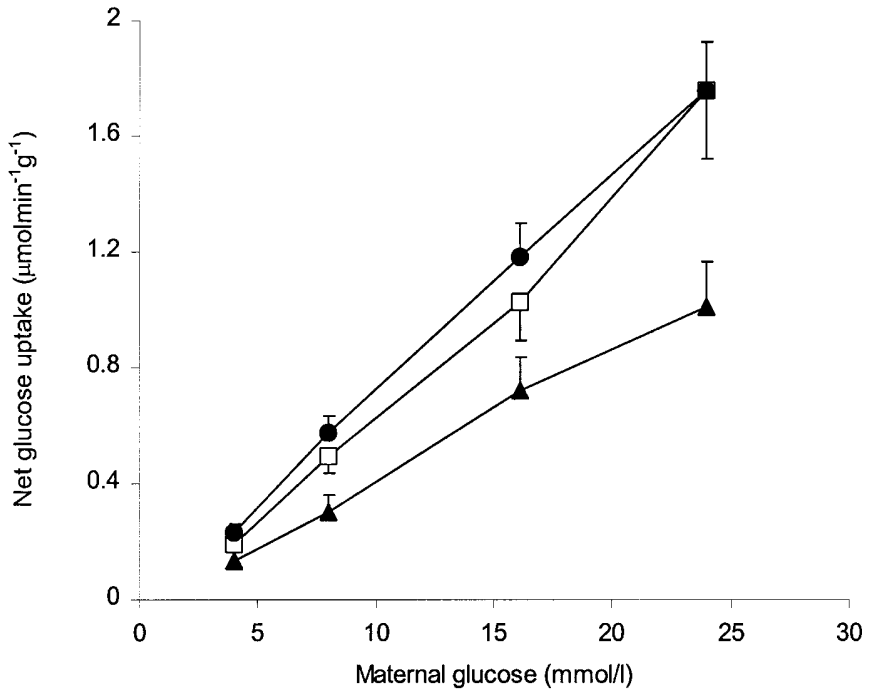

Fig. 1. Net glucose uptake from the maternal perfusate of human in vitro perfused placentae $\left(\mu \operatorname{molmin}^{-1} \mathrm{~g}^{-1}\right)$ at maternal glucose concentrations of $4,8,16$ and $24 \mathrm{mmol} / \mathrm{l}$. Placentae from GDM pregnancies involving diet intervention alone $(\boldsymbol{\Delta})$ had significantly reduced uptake compared to placentae from GDM pregnancies treated with insulin ( $)$ ANOVA $p<0.001)$ and non-diabetic controls $(\square$; ANOVA $p<0.001)$. There was no significant difference between the GDM-Insulin and the control groups. A $t$ test showed that the GDM-Diet group significantly differed from the Control group at glucose concentrations of 8 and $24 \mathrm{mmol} / \mathrm{l}$ and that the GDM-Diet group significantly differed from the GDM-Insulin group at glucose concentrations of 8,16 and $24 \mathrm{mmol} / \mathrm{l}$

$0.52 \pm 0.10,0.98 \pm 0.12,1.73 \pm 0.32,2.70 \pm 0.55, \mathrm{n}=9$, GDM-Diet group, $0.44 \pm 0.09,0.63 \pm 0.14,1.34 \pm$ $0.24,1.88 \pm 0.41, \mathrm{n}=10$ and GDM-Insulin group, $0.58 \pm 0.12,1.03 \pm 0.19,1.98 \pm 0.37,2.89 \pm 0.60, n=9$. Placental glucose utilisation (Fig. 3 ) rose with increasing maternal glucose concentrations for the non-diabetic control subjects ( $p<0.001$; one-way ANOVA), but did not change with maternal glucose concentration for the GDM-Diet group and GDM-Insulin group. Placental glucose utilisation was not significantly different between the GDM-Insulin and GDM-Diet groups but both were significantly reduced compared with the control group $(p<0.001)$.

The release of lactate from the placental lobule into the fetal and maternal effluents (Fig. 4) was independent of maternal glucose concentration. For all groups of placentae the release of lactate into the maternal effluent was higher than into the fetal effluent $(p<0.001)$. Release of lactate into the maternal compartment of placentae from the GDM-Diet group was reduced compared to the control group $(p<0.001)$ and GDM-Insulin group $(p<0.005)$ but there was no significant difference between the control and GDM-Insulin groups. Release of lactate into the fetal effluent of placentae for the GDMDiet group $(p<0.005)$ and the GDM-Insulin group $(p<0.001)$ was reduced compared to the control

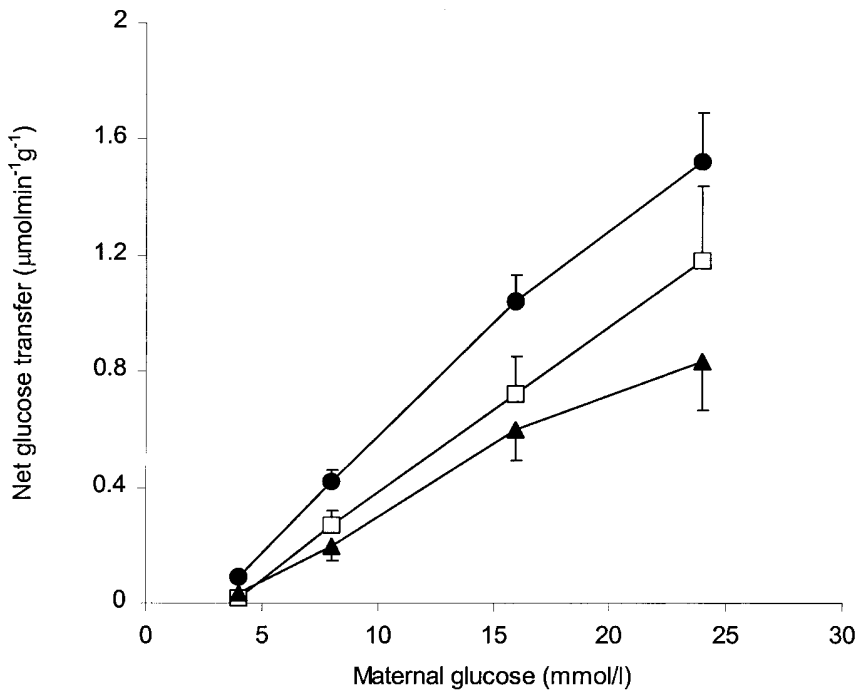

Fig. 2. Net glucose transfer to the fetal effluent of human in vitro perfused placentae $\left(\mu\right.$ molmin $\left.{ }^{-1} \mathrm{~g}^{-1}\right)$ at maternal glucose concentrations of $4,8,16$ and $24 \mathrm{mmol} / \mathrm{l}$. Placentae from GDM pregnancies treated with insulin (O) had significantly increased net transfer compared to placentae from GDM pregnancies involving diet intervention alone ( $\boldsymbol{\Delta}$, ANOVA $p<0.001)$. Placentae from non-diabetic controls $(\square)$ were not significantly different from either GDM group. A $t$ test showed that the GDM-Insulin group significantly differed from the GDM-Diet group at all glucose concentrations

group. The release of lactate into the fetal circulation for the two GDM groups was not significantly different.

The transfer of ${ }^{3} \mathrm{H}$-L-glucose from the maternal perfusate into the fetal circulation (Fig. 5) was independent of maternal glucose concentration. Both the GDM-Insulin group $(p<0.05)$ and GDM-Diet group $(p<0.005)$ had reduced ${ }^{3} \mathrm{H}-\mathrm{L}-$ glucose transfer compared to the control group. The transfer of ${ }^{3} \mathrm{H}-\mathrm{L}-\mathrm{glu}-$ cose for the two GDM groups was not significantly different.

There was no significant difference in total placental net transfer of glucose to the fetal circulation between the three groups at a maternal glucose concentration of $8 \mathrm{mmol} / \mathrm{l}$. Means $\pm \mathrm{SEM}$ values for total placental net transfer $\left(\mu \mathrm{molmin}^{-1}\right.$ [total placental weight $]^{-1}$ ) were: control group $178.4 \pm 38.2 n=8$, GDM-Diet group $136.7 \pm 30.1 n=10$ and GDM-Insulin group $239.5 \pm 19.8 n=8$.

\section{Discussion}

Our results add further weight to our previous observation that glucose handling by the placenta alters in women who are pregnant and have GDM compared with women who have a normal pregnancy [7]. In ad- 


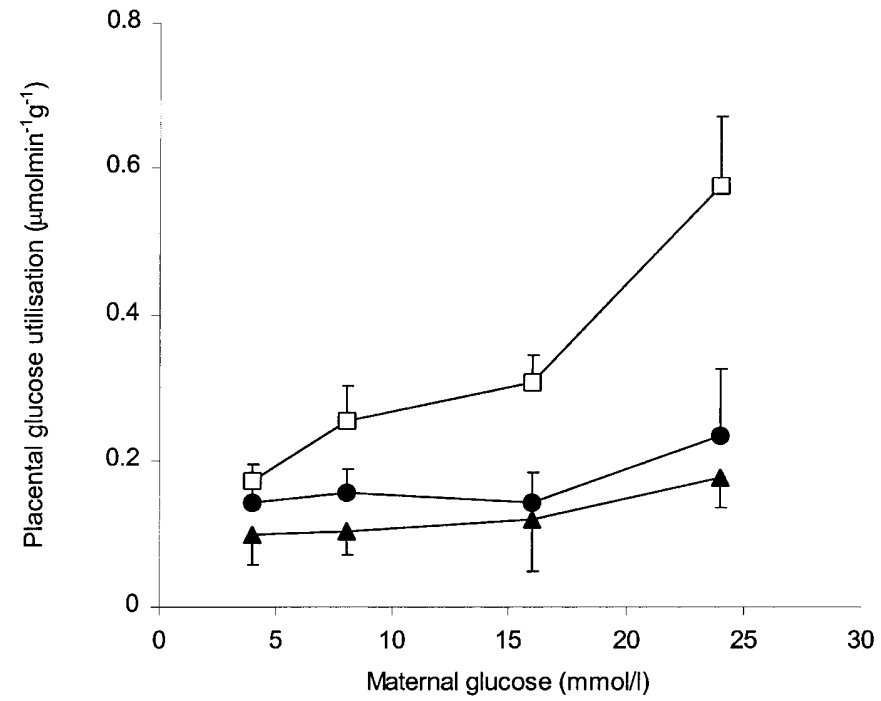

Fig. 3. Net glucose utilisation by human in vitro perfused placentae $\left(\mu\right.$ molmin ${ }^{-1} \mathrm{~g}^{-1}$ ) at maternal glucose concentrations of $4,8,16$ and $24 \mathrm{mmol} / \mathrm{l}$. Placentae from GDM pregnancies involving diet intervention alone $(\boldsymbol{\Delta}$, ANOVA $p<0.001)$ and insulin treatment $(\boldsymbol{O}$, ANOVA $p<0.001)$ had significantly reduced utilisation compared to non-diabetic control subjects $(\square)$. There was no significant difference between the two GDM groups. A $t$ test showed that the GDM-Diet group significantly differed from the control group at glucose concentrations of 8,16 and $24 \mathrm{mmol} / \mathrm{l}$ and that the GDM-Insulin group significantly differed from the control group at glucose concentrations of 16 and $24 \mathrm{mmol} / \mathrm{l}$

dition, this study suggests that glucose handling by placentae from GDM pregnancies is different depending on whether the women received insulin therapy or not. Glucose uptake from the maternal perfusate was reduced for the GDM-Diet group compared with the GDM-Insulin and control groups. Transfer to the fetal circulation for the GDM-Diet group was lower than in the GDM-Insulin group. By contrast placental metabolism (net glucose utilisation) was not significantly different between the two GDM groups but it was different from the non-diabetic control subjects. These results indicate that placental function is altered in the placentae of insulin-treated GDM patients compared with GDM patients not receiving insulin. This difference between the GDM groups could be due to the direct effect of insulin, for example through up-regulation of GLUT1 transporters. It could also be due to the secondary effects of insulin on maternal circulation, for example, alterations in plasma glucose concentrations or other factors. In addition, events before insulin treatment, such as differences in the severity of the glucose intolerance or other still to be determined differences between placentae, could play a part in changes in placental glucose handling. Insulin treatment during GDM could tend to normalise placental glucose transfer, although it is not clear whether this is advantageous for the fetus.

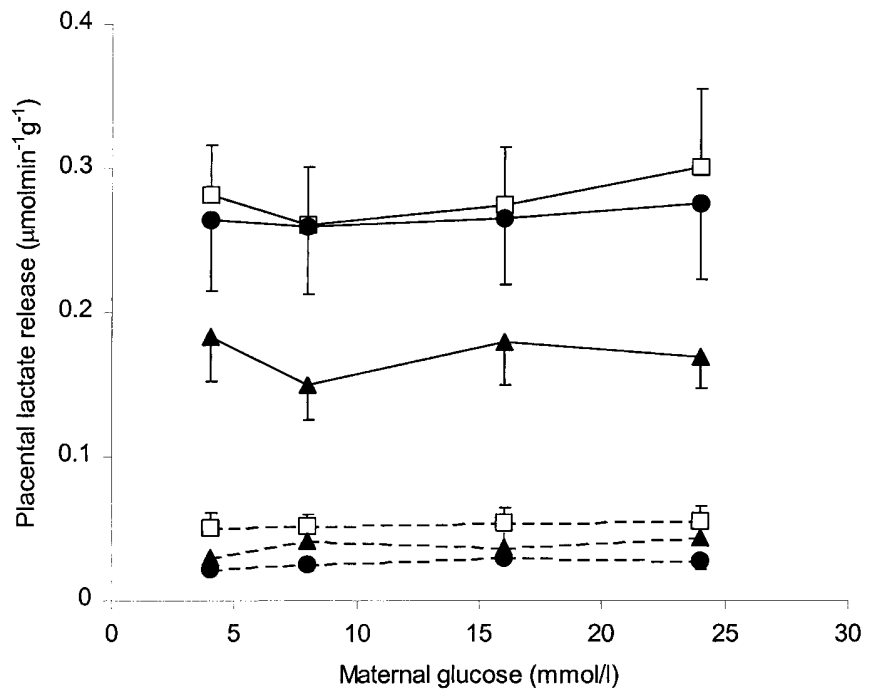

Fig. 4. Lactate release into the fetal and maternal effluents by human in vitro perfused placentae $\left(\mu\right.$ molmin $\left.^{-1} \mathrm{~g}^{-1}\right)$ at maternal glucose concentrations of $4,8,16$ and $24 \mathrm{mmol} / \mathrm{l}$. Placentae from GDM pregnancies involving diet intervention alone $(-)$ had significantly reduced lactate release into the maternal effluent compared to non-diabetic controls ( $-\square-$, ANOVA $p<0.001)$ and GDM pregnancies treated with insulin $(-$, ANOVA $p<0.005)$. There was no significant difference between the insulin-treated GDM group and the Control group. Placentae from GDM pregnancies with diet intervention alone (---, ANOVA $p<0.01)$ and with insulin treatment $(----$ ANOVA $p<0.001)$ had significantly reduced lactate release into the fetal circulation compared to non-diabetic controls (--- ---). There was no significant difference between the two GDM groups. A $t$ test showed that the maternal lactate release for the GDM-Diet group significantly differed from the control group at glucose concentrations of 4,8 and $24 \mathrm{mmol} / \mathrm{l}$. Although the ANOVA identified an overall significant difference between the GDM-Diet and GDM-Insulin groups for maternal lactate release, a $t$ test did not show any significant differences at individual glucose concentrations. A $t$ test showed that the fetal lactate release for the GDM-Insulin group significantly differed from the Control group at glucose concentrations of 4,8 and $24 \mathrm{mmol} / \mathrm{l}$. Although the ANOVA identified an overall significant difference between the GDM-Diet and control groups for fetal lactate release, a $t$ test did not show any significant differences at individual glucose concentrations

Another study used a similar approach to investigate glucose handling by in vitro perfused placentas [7]. The latter study found significant reductions in mean net glucose transfer and direct materno-fetal transfer in a GDM-Diet group compared with the non-diabetic control group. Although our study identified similar differences in the two functions between the GDM-Diet and control groups, these were not significant. The different results could be due to differences in the characteristics of the sample groups, for example the degree of maternal glycaemic control. In addition, the former study pooled the data from the groups to test for variation with changing glucose concentration. In this study, the test for varia- 


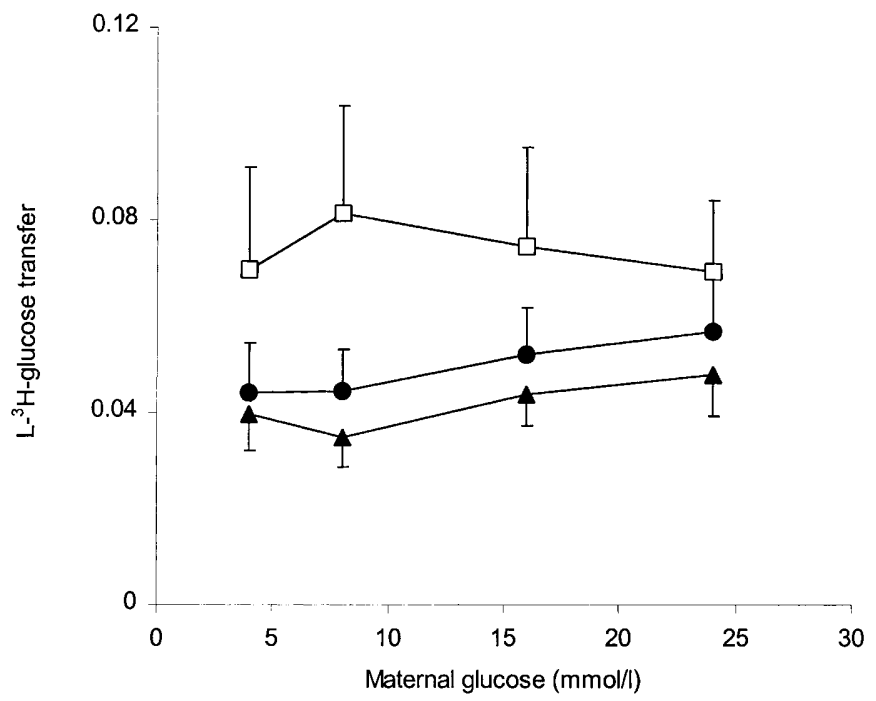

Fig. 5. The ratio of $\mathrm{L}^{3}{ }^{3} \mathrm{H}$-glucose infused into the maternal perfusate that is detected in the fetal effluent. This is a measure of non-facilitated diffusion. Placentae from GDM pregnancies involving diet intervention alone $(\boldsymbol{\Lambda}$, ANOVA $p<0.005)$ and GDM pregnancies involving insulin treatment ( $)$, ANOVA $p<0.05)$ had reduced $\mathrm{L}^{3} \mathrm{H}$-glucose transfer, compared to non-diabetic control subjects $(\square)$. There was no significant difference between the two GDM groups. Although the ANOVA identified an overall significant difference between the GDMDiet and control groups and the GDM-Insulin and Control groups, a $t$ test did not show any significant differences at individual glucose concentrations

tion with changing glucose concentration was carried out on the data from each group separately.

The part that insulin plays in human placental function is not clear. Insulin receptors and several proteins associated with insulin receptor signalling pathways have been identified in human term placenta [11]. Some evidence suggests that insulin could directly affect placental glucose handling. Insulin at physiological concentrations increased the rate of glucose uptake into cultured first trimester trophoblasts by increasing the concentration of GLUT1 expression [8]. In other studies, however, the infusion of insulin into the maternal or fetal compartments during the course of placental perfusion had no effect on glucose transport and metabolism $[12,13]$.

Studies investigating the location of the insulin receptor within the human placenta have shown that the syncytiotrophoblast expresses a very low concentration of surface insulin receptor at term and that the majority of insulin receptors are located on the endothelium lining vessels of the fetal circulation. This is in contrast to the first trimester when only the maternal-facing surface of the placenta has insulin receptors [11]. This evidence suggests that the capacity for insulin in the maternal circulation to affect placental function directly decreases during the course of pregnancy. Differences have been found in insulin binding between placentae from women with GDM and women with normal pregnancies. Such relative resistance of the placenta to the effects of insulin could help to ensure that under conditions of fetal hyperinsulinaemia, the fetus still receives an adequate supply of glucose from the placenta. Indeed, this is compatible with our findings, that placental glucose utilisation in GDM is not normalised by insulin. Insulin binding in total trophoblast plasma membrane fractions was found to be reduced by $30 \%$ in plasma membranes from a diet-treated GDM group and increased by $90 \%$ in an insulin-treated GDM group compared with a control non-diabetic group [14].

In addition to maternal administration of insulin during GDM directly affecting placental glucose handling, it is possible that insulin acts indirectly by altering maternal plasma glucose concentrations. Hyperglycaemia has been shown to reduce cultured human term trophoblast cell glucose uptake through a reduction in GLUT1 protein expression and translocation of GLUT1 away from the cell surface $[15,16]$. The glycated haemoglobin measurements in this study suggest that long-term glycaemic control was not different between the two GDM groups. However, a reduction in glucose transport in placentae from the GDM-Diet group in this study could be due to acute periods of hyperglycaemic exposure throughout the pregnancy. Thus, in a similar manner to the effects of acute hyperglycaemia in cultured cells, hyperglycaemia in vivo during GDM could induce changes in expression and location of placental GLUT1.

Indices of placental glucose metabolism were also measured in this study. Net glucose utilisation was reduced in both GDM groups compared with non-diabetic control subjects and did not increase markedly with increased maternal glucose concentration. Lactate release from the perfused placenta has previously been measured but the comparison of GDM and normal placentae has not been studied [17]. Placental lactate production by the placenta is a normal, aerobic process and not the result of oxygen deficit [18]. Maternal lactate release was reduced in the GDM diet group, but not in the GDM insulin group, whereas placental glucose utilisation was reduced in both groups. This suggests that changes in other metabolic processes (in addition to lactate production) could be occurring leading to similar placental glucose utilisation in the two GDM groups. For example, there could be changes in glycogen turnover in GDM placentae. It is worth noting that GLUT4 (the insulin sensitive transporter) and insulin receptors have been co-localised to the same cell types within the placenta, suggesting that insulin could have an influence on glycogen accumulation in specific placental cells [19].

Non-facilitated L-glucose diffusion was reduced in both GDM groups. This factor is influenced by syncytiotrophoblast surface area, permeability, and thickness of the basement membranes and degree of vas- 
cularisation of the villous tree. Histological studies have shown that placentae from poorly controlled GDM pregnancies show a thickening of the basement membranes and reduced vascularisation of the villi $[11,20]$. The reduction of non-facilitated glucose diffusion in both GDM groups suggests that differences in placental structure between normal and GDM pregnancies could be established before insulin therapy and that insulin does not markedly alter it.

In summary, this study has shown that transplacental glucose transport is reduced in term placentae of patients with GDM controlled by diet alone compared with GDM patients requiring and receiving insulin treatment.

Acknowledgements. This work was supported by the Pratt Foundation, Diabetes Australia, the Royal Women's Hospital 3AW Community Services Trust and a Project Grant (number 9835507) from the Australian National Health and Medical Research Council. We also gratefully acknowledge the help of the clinical research midwives, M. Grehan, N. Davies, S. Walker, S. Bishop, M. Stewart, T. Nielsen and S. Nisbett, and the midwifery and obstetric staff of the Royal Women's Hospital.

\section{References}

1. Stone C, Halliday J (1999) Gestational diabetes incidence in Victoria, 1996. Proceedings book of the Perinatal Society of Australia and New Zealand 3rd Annual Congress: A112 Abstract

2. Mose R, Griffith R, McPherson S (1994) The incidence of gestational diabetes in the Illawarra area of New South Wales. Aust N Z J Obstet Gynaecol 36: 239-247

3. Beischer NA, Oats JN, Henry OA, Sheedy MT, Walstab JE (1991) Incidence and severity of gestational diabetes mellitus according to country of birth in women living in Australia. Diabetes 40 [Suppl 2]: 35-38

4. Strauss R (1997) Effects of the intrauterine environment on childhood growth. Br Med Bull 53: 81-95

5. Cox NJ (1994) Maternal component in NIDDM transmission: How large an effect? Diabetes 43: 166-168

6. Pettitt DJ, Aleck KA, Baird HR, Carraher MJ, Bennett PH, Knowler WC (1988) Congenital susceptibility to NIDDM: role of intrauterine environment. Diabetes 37: 622-627

7. Osmond DTD, Nolan CJ, King RG, Brennecke SP, Gude NM (2000) Effects of gestational diabetes on human placental glucose uptake, transfer and utilisation. Diabetologia 43: 576-582
8. Gordon MC, Zimmerman PD, Landon MB, Gabbe SG, Kniss DA (1995) Insulin and glucose modulate glucose transporter messenger ribonucleic acid expression and glucose uptake in trophoblasts from first-trimester chorionic villi. Am J Obstet Gynecol 173: 1089-1097

9. Hoffman L, Nolan C, Wilson JD, Oats JJN, Simmons D (1998) Gestational diabetes mellitus - management guidelines: The Australasian Diabetes in Pregnancy Society. Med J Aust 169: 93-97

10. Gude NM, Xie CY, King RG et al. (1993) Effects of eicosanoid and endothelial cell derived relaxing factor inhibition on fetal vascular tone and responsiveness in human perfused placenta. Trophoblast Research 7: 133-145

11. Desoye G, Shafrir E (1996) The human placenta in diabetic pregnancy. Diabetes Rev 4: 70-89

12. Challier JC, Hauguel S, Desmaizieres V (1986) Effect of insulin on glucose uptake and metabolism in the human placenta. J Clin Endocrinol Metab 62: 803-807

13. Urbach J, Mor L, Ronen N, Brandes JM (1989) Does insulin affect placental glucose metabolism and transfer? Am J Obstet Gynecol 161: 953-959

14. Desoye G, Hofmann HH, Weiss PAM (1992) Insulin binding to trophoblast plasma membranes and placental glycogen content in well-controlled gestational diabetic women treated with diet or insulin, in well-controlled overt diabetic patients and in healthy control subjects. Diabetologia 35: $45-55$

15. Hahn T, Barth S, Weiss U, Mosgoeller W, Desoye G (1998) Sustained hyperglycaemia in vitro down-regulates the GLUT1 glucose transport system of cultured human term placental trophoblast: a mechanism to protect fetal development? FASEB J 12: 1221-1231

16. Hahn T, Hahn D, Blaschitz A, Korgun ET, Desoye G, Dohr G (2000) Hyperglycaemia-induced subcellular redistribution of GLUT1 glucose transporters in cultured human term placental trophoblast cells. Diabetologia 43: $173-180$

17. Hauguel S, Desmaizieres V, Challier JC (1986) Glucose uptake, utilisation and transfer by human placenta as functions of maternal glucose concentrations. Pediatr Res 20: 269-273

18. Hay WW, Sparks JW (1985) Placental, fetal and neonatal carbohydrate metabolism. Clin Obstet Gynecol 28: 473-485

19. Xing AY, Challier JC, Lepercq J et al. (1998) Unexpected expression of glucose transporter 4 in villous stromal cells of human placenta. J Clin Endocrinol Metab 83: 4097-4101

20. Al-Okail MS, Al-Attas OS (1994) Histological changes in placental syncytiotrophoblasts of poorly controlled gestational diabetic patients. Endocr J 41: 355-360 